\title{
Common carotid ligation for the treatment of ruptured posterior communicating aneurysms
}

\author{
R. V. JEFFREYS ${ }^{1}$ AND A. E. HOLMES \\ From the Department of Neurological Surgery, Addenbrooke's Hospital, Cambridge
}

SUMMARY Sixty-four consecutive cases of ruptured posterior communicating aneurysms were investigated. Fifty-one cases were treated by abrupt ligation of the common carotid artery with no operative mortality and a small temporary operative morbidity.

Any operation for the treatment of ruptured intracranial aneurysms must be judged on the operative mortality and morbidity, and its efficacy in preventing further subarachnoid haemorrhage. Many papers that discuss the value and risks of the operation of carotid ligation emphasize the fact that it has been performed for aneurysms not only of the posterior communicating artery but of other intracranial arteries, and it is difficult to judge the merits of the procedures for aneurysm of one site. This study comprises 64 patients with ruptured posterior communicating aneurysms of which 51 have been treated by immediate ligation in continuity of the common carotid artery. There was no operative mortality and only a small temporary operative morbidity.

\section{PATIENTS}

Between the years 1961 and 196964 cases of ruptured aneurysm of the posterior communicating artery were admitted. All these patients had had a subarachnoid haemorrhage proven by lumbar puncture, and angiography demonstrated an aneurysm at the origin of the posterior communicating artery from the internal carotid artery. The selection of patients for admission to the Neurosurgical Unit was dependent on the referring physicians.

We now present the details of the 51 patients who underwent carotid artery ligation. Bilateral carotid angiography was performed on all these patients and, in 10 , unilateral vertebral angiograms were performed in addition. Twenty-seven of the aneurysms were on the right side and 24 on the left and there were nine cases with multiple aneurysms. There were 16 men and 35 women, a ratio of more than two to one in favour of women. The age incidence is demonstrated in Table 1 where it can be seen that over half the patients were more than 50 years old. From the angiograms it was established by cross compression tests that a satisfactory anatomical pathway existed across the anterior part of 'Present address: Department of Neurosurgery, The London Hospital, Whitechapel, London.
TABLE 1

AGE INCIDENCE OF PATIENTS UNDERGOING CAROTID ARTERY LIGATION

\begin{tabular}{|c|c|c|}
\hline Age (yr.) & Patients & \\
\hline \multirow[t]{2}{*}{$\begin{array}{l}15-25 \\
25-35 \\
35-45 \\
45-55 \\
55-65\end{array}$} & $\begin{array}{r}1 \\
4 \\
10 \\
14 \\
22\end{array}$ & $\begin{array}{l}20 \\
27 \\
8\end{array}$ \\
\hline & 51 & 16 \\
\hline
\end{tabular}

the circle of Willis. Absence of cross-flow was regardef as the only radiological finding that might have alteres the decision to ligate the carotid artery. In those case with multiple aneurysms the decision as to which on had ruptured was based upon both clinical correlation and the demonstration of local spasm in the angiograms.

Thirty-two patients had one recent subarachnoid haemorrhage before surgery, 16 had two haemorrhages, and three patients had three haemorrhages. Table 2 shows the time intervals from the first and from the last subarachnoid haemorrhage to surgery; those patients with only one haemorrhage being included in both Tables. It can be seen that $50 \%$ of patients were operated on less than 20 days from the first haemorrhage and $78 \%$ less

TABLE 2

TIME OF SUBARACHNOID HAEMORRHAGE (SAH) TO CAROTID ARTERY LIGATION

\begin{tabular}{|c|c|c|c|c|}
\hline \multirow[t]{2}{*}{ Days } & \multicolumn{2}{|c|}{$\begin{array}{c}\text { Time from lst } S A H \text { to } \\
\text { surgery }\end{array}$} & \multicolumn{2}{|c|}{$\begin{array}{c}\text { Time from last } S A H \text { to } \\
\text { surgery }\end{array}$} \\
\hline & Patients & $\%$ & Patients & $\%$ \\
\hline $\begin{array}{l}0-5 \\
5-10 \\
10-15 \\
15-20 \\
20-25 \\
\text { More than } 25\end{array}$ & $\begin{array}{r}0 \\
7 \\
12 \\
8 \\
8 \\
16\end{array}$ & $\begin{array}{r}0 \\
14 \\
23 \\
16 \\
16 \\
31\end{array}$ & $\begin{array}{r}5 \\
12 \\
13 \\
9 \\
5 \\
7\end{array}$ & $\begin{array}{l}10 \\
23 \\
25 \\
18 \\
10 \\
14\end{array}$ \\
\hline & 51 & 100 & 51 & 100 \\
\hline
\end{tabular}


than 20 days from the last subarachnoid haemorrhage. The majority of recurrent haemorrhages occurred between the 10th and 15 th day after the first bleed. Clinically, a modified Botterell classification (Hunt and Hess, 1968) has been used to evaluate the neurological state immediately before surgery and the findings are contained in Table 3. This shows that the majority of patients were in grades 1 and 2, although two cases were in grade 5 at the time of surgery.

TABLE 3

BOTTERELL CLASSIFICATION ON DAY OF SURGERY

\begin{tabular}{ccr}
\hline Grade & Patients & $\%$ \\
\hline 1 & 7 & 14 \\
2 & 29 & 57 \\
3 & 13 & 25 \\
4 & 0 & 0 \\
5 & 2 & 4 \\
\hline & 51 & 100 \\
\hline
\end{tabular}

The timing of operation was decided by clinical assessment of the patient from day to day. In the majority of cases operation was delayed until they had improved to grades 1 or 2 . However, if a patient showed no significant change over a number of days operation was performed irrespective of their clinical grading. In exceptional circumstances, ligation was performed on a deteriorating patient if it was proven that deterioration was due to repeated haemorrhage rather than spasm or intracerebral haematoma.

\section{OPERATIVE TECHNIQUE}

Ligation of the common carotid artery was performed under local anaesthesia. Mild preoperative sedation was usually given to ensure that all patients were fully cooperative for neurological assessment throughout the procedure. The neurological findings were checked after the administration of any sedation and before towelling up. The common carotid artery was then exposed through a small transverse skin crease incision situated at the level of the cricoid cartilage and 3 to $4 \mathrm{~cm}$ proximal to the carotid bifurcation. Chinese twisted silk ligatures were passed loosely around the vessel and, after a final neurological assessment, a Crile's non-crushing clamp totally and immediately occluded the vessel. Neurological assessment was carried out immediately after occlusion and at frequent intervals during the next 30 minutes. In no case during the trial period was it necessary to release the clamp and in all 51 patients it was possible to ligate the vessel in two places in continuity.

\section{RESULTS}

Forty-seven patients $(92 \%)$ showed no increase in their neurological signs and only four $(8 \%)$ showed minor changes, such as slight increase of distal weakness or a change of plantar response. All these changes had cleared completely within two weeks of the operation. If a major deficit had occurred at the time of operation the clamp would have been released immediately and the operation abandoned. There was no operative mortality. Before operation 19 patients had an oculomotor lesion, either partial or complete, of which 10 went on to full recovery after operation. Twenty patients had a preoperative hemiparesis and 16 of these recovered completely (Table 4).

TABLE 4

END RESULT OF NEUROLOGICAL DEFICIT PRESENT BEFORE OPERATION

\begin{tabular}{lcc}
\hline & 3rd nerve palsy & Hemiparesis \\
\hline $\begin{array}{l}\text { Number of cases } \\
\text { Recovery after operation }\end{array}$ & 19 & 20 \\
$\begin{array}{l}\text { No or partial recovery after } \\
\text { operation }\end{array}$ & 10 & 16 \\
\hline
\end{tabular}

Of these patients, $80 \%$ have been followed up for two years or longer. Forty-seven $(92 \%)$ of the 51 patients are still alive and four $(8 \%)$ are dead. Two $(4 \%)$ died from bronchopneumonia long after operation and unrelated to it and two (4\%) died as a result of recurrent subarachnoid haemorrhage, one from the same aneurysm five years after carotid ligation and one from a small unrecognized aneurysm of the contralateral anterior communicating artery 18 months after carotid ligation. At the present time there have been no other cases of major recurrent subarachnoid haemorrhage in the survivors. Forty patients $(79 \%)$ are back at their old job, six $(11 \%)$ have a lighter job, and five $(10 \%)$ have retired at the age of 65 .

INTERESTING CASES Several of the patients are worth comment because of the particular therapeutic problems they presented. One woman who was 34 weeks pregnant at the time of her first subarachnoid haemorrhage was treated conservatively and not investigated, and went on to have a Caesarian section at 38 weeks with tubal ligation. However, four days after this operation she had a second subarachnoid haemorrhage, was then investigated and proceeded to carotid artery ligation. A second woman with a congenital right spastic hemiplegia after birth trauma suffered her first subarachnoid haemorrhage from an aneurysm of the right posterior communicating artery and the right common carotid artery was successfully ligated without further neurological upset. One young man of 26 suffering from polycystic renal disease with systemic hypertension underwent carotid artery ligation without ill effect, and one patient was so severely incapacitated by 
chest disease that he was unable to lie flat and had his ligation of the common carotid artery performed sitting up.

CASES NOT TREATED BY CAROTID LIGATION The policy of this Unit has been to treat ruptured aneurysms of the posterior communicating artery by ligation of the common carotid artery and to reserve intracranial surgery for those cases with multiple aneurysms, or associated intracerebral haematomata. There were seven cases treated by direct attack with three deaths in the postoperative period. Six of these had associated intracerebral haematomata and one another aneurysm of the middle cerebral artery. In addition, four cases have been treated conservatively. The reasons for this were severe coronary artery disease, open pulmonary tuberculosis, cerebral infarction, and finally a case with four aneurysms. Two other cases died from recurrent subarachnoid haemorrhage before planned carotid ligation was undertaken and their deaths could be said to be due directly to delay in surgical intervention.

\section{DISCUSSION}

The purpose of this communication is to discuss the risk of a specific method of treatment of subarachnoid haemorrhage from an aneurysm at the origin of the posterior communicating artery from the internal carotid artery. McKissock, Richardson, and Walsh (1960) have shown the advantages of carotid artery ligation over conservative treatment for this particular aneurysm with regard to survival. Mount (1959) found difficulty in effecting abrupt occlusion of the vessel in about a third of his cases without causing profound neurological deficit and for this reason preferred gradual occlusion using a Silverstone clamp. In the combined series (Nishioka, 1966) 201 cases had neurological complications after carotid artery ligation and about two thirds of these after abrupt occlusion. In addition, he also showed that ligation of the common carotid artery is less likely to cause neurological complication than ligation of the internal carotid artery but may be less effective in preventing recurrent haemorrhage.

In the other series which are comparable, the operative mortality varies from $6 \%$ of German and Black (1965), $8 \%$ of McKissock et al. (1960), $10 \%$ of Harris and Udvarhelyi (1957), to $15 \%$ of the combined series (Nishioka, 1966). In our series there was no operative mortality as such, but we have accepted in this category the two patients who died from recurrent haemorrhage while awaiting planned carotid surgery (3.5\%).

In the series already quoted the morbidity of significant neurological deficit, much of which remained permanently, ranged from $20 \%$ for $\stackrel{\Phi}{=}$ McKissock et al. (1960) to $28 \%$ in the combined series (Nishioka, 1966). These figures are to be compared with the minor and temporary changes which occurred in only $8 \%$ of our patients. We have not had to discard any patient from our series because of the demonstration of poor cross-flow through the circle of Willis, but note that Harris and Udvarhelyi . (1957) had a high incidence of hemiparesis in $11 \overrightarrow{\vec{F}}$ patients who had only a poor or absent cross-flow at angiography. Although it is not possible to ascertain accurately when ligation was performed on these patients, it seems that the operation was done at a much earlier stage than in our cases.

These figures for carotid ligation have in turn to be compared with those of a direct attack upon the $\vec{\circ}$ aneurysm. Paterson (1968) made a direct attack on 77 cases of aneurysm of the posterior communicating $\vec{\omega}$ artery and had an operative mortality of $10 \%$ and a serious morbidity of $12 \%$. It must also be pointed out that some of these patients had unruptured aneurysms.

Although $80 \%$ of our cases have been followed up for two years or more, we feel this is probably to short a period to comment accurately on the success of carotid artery ligation in preventing late recurren $\vec{S}$ subarachnoid haemorrhage. In the published series already quoted there is a wide range of variation for recurrent haemorrhage between $3 \%$ and $20 \%$ and we feel that some of this is due to the difference it. length of follow up. In the two cases we describe $\vec{\theta} \overrightarrow{0}$ that had recurrent haemorrhage one was from unsuccessful treatment of an aneurysm which continued to enlarge and the other was from a previously unsuspected contralateral aneurysm, the development of which was probably influenced by the haemodynamic change resulting from carotid artery ligation.

We have not performed routine check postoperative angiography. However Tindall, Goree, Lee, and Odom (1966) have done so in 41 cases of common carotid artery ligation, to find in 19 that the aneurysm was much smaller, in nine the aneurysm unchanged, and in one the aneurysm actually larger, these angiograms being performed at various time intervals after surgery.

\section{CONCLUSION}

Although some neurosurgeons for a long time have advocated ligation of the common carotid artery for aneurysms of the posterior communicating artery, $N$ more recently this method of treatment has been questioned because of an unacceptable operative morbidity and the disadvantage that recurrent sub- 
arachnoid haemorrhage is prevented by an indirect method. We would like to suggest that it is both a safe and an effective method of treatment. It would seem that there is considerable benefit to be gained by waiting preoperatively for neurological improvement at the expense of a small risk of recurrent haemorrhage. By comparison direct attack carries a higher mortality and morbidity for the possible advantage of the knowledge of definite occlusion of the aneurysm.

We are grateful to Mr. Walpole Lewin and Mr. John Gleave, under whose care the patients were treated, for their helpful criticisms.

\section{REFERENCES}

German, W. J., and Black, S. P. W. (1965). Cervical ligation for internal carotid aneurysms. An extended follow-up. J. Neurosurg., 23, 572-577.
Harris, P., and Udvarhelyi, G. B. (1957). Aneurysms arising at the internal carotid-posterior communicating artery junction. J. Neurosurg., 14, 180-191.

Hunt, W. E., and Hess, R. M. (1968). Surgical risk as related to time of intervention in the repair of intracranial aneurysms. J. Neurosurg., 28, 14-20.

McKissock, W., Richardson, A., and Walsh, L. (1960). 'Posterior communicating' aneurysms. Lancet, 1, 12031206.

Mount, L. A. (1959). Results of treatment of intracranial aneurysms using the Selverstone clamp. J. Neurosurg., 16, 611-618.

Nishioka, H. (1966). Results of the treatment of intracranial aneurysms by occlusion of the carotid artery in the neck. J. Neurosurg., 25, 660-682.

Paterson, A. (1968). Direct surgery in the treatment of posterior communicating aneurysms. Lancet, 2, 808-811.

Tindall, G. T., Goree, J. A., Lee, J. F., and Odom, G. L. (1966). Effect of common carotid ligation on size of internal carotid aneurysms and distal intracarotid and retinal artery pressures. $J$. Neurosurg., 25, 503-511. 